\title{
Baited-camera observations of deep-sea megafaunal scavenger ecology on the California slope
}

\author{
John Yeh* ${ }^{*}$ Jeffrey C. Drazen \\ University of Hawai'i, Department of Oceanography, 1000 Pope Rd., Honolulu, Hawaii 96822, USA
}

\begin{abstract}
Baited cameras have offered much insight into the ecology of scavenging animals in several parts of the worlds' oceans, revealing patterns of vertical zonation, trends in size and abundance with depth, and aspects of feeding behavior. It is surprising, then, that very little has been published on the scavenging community off the eastern Pacific continental slope, where work of this nature originated. Here we present a study of megafaunal scavenger ecology encompassing a wide range of taxa from shelf to abyssal depths off central California. During 13 baited camera deployments from 105 to $3144 \mathrm{~m}$, we photographed 25 scavenging taxa, consisting mainly of fish and crabs. Combined with trawl results, these data showed that prevalence of scavenging in fishes increased from $2 \%$ of all species at $100 \mathrm{~m}$ to $46 \%$ of all species at $3000 \mathrm{~m}$, suggesting more opportunistic feeding habits and the increasing importance of carrion as a food source at greater depths. Of 4 scavenging fish species examined, 3 (Antimora microlepis, Albatrossia pectoralis, and Anoplopoma fimbria) displayed significant increases in length with increased depth while Coryphaenoides acrolepis displayed an opposite, 'smaller-deeper' trend. Estimates of fish density generated from camera first arrival times and trawl data were compared, yielding no significant correlation. During one camera deployment, $C$. armatus was used as bait, which resulted in the complete absence of $C$. armatus, while a peak abundance of 11 individuals was observed at similar depths/locations using nonmacrourid bait. The depth-related patterns in scavenger species richness and intraspecific size-depth trends differ from those in the North Atlantic, suggesting that further regional comparisons are needed to better understand scavenger ecology on a global scale.
\end{abstract}

KEY WORDS: Scavenger $\cdot$ Deep sea $\cdot$ Size trends $\cdot$ Abundance estimate $\cdot$ Baited camera Resale or republication not permitted without written consent of the publisher

\section{INTRODUCTION}

Megafaunal scavengers comprise a ubiquitous component of life in the deep sea. From invertebrates to elasmobranchs, scavengers of all sizes fulfill an important ecological function by dispersing and remineralizing large food falls that reach the seafloor and, in turn, enhancing the surrounding particulate and dissolved organic matter pool (Stockton \& De Laca 1982, Smith 1985, Priede et al. 1991, Drazen et al. 2008). Scavengers are active foragers of carrion (Britton \& Morton 1994). Accordingly, scavenger studies have primarily utilized baited experiments mainly with cameras - for data collection (Bailey et al. 2007). Baited camera work originated in California with the 'monster camera' (Isaacs 1969, Isaacs \& Schwartzlose 1975); surprisingly however, a quantitative community-wide scavenger study along the continental margin of this region has yet to emerge. Sampling effort in this area has mainly focused on single species and targeted abyssal depths (Priede et al. 1990, 1991, 1994, 2003). Elsewhere, scavenger ecology of the continental rise and abyssal plains of the NE Atlantic has been well described in studies that focused predominantly on ichthyofauna. As a result, substantial information has been published on the composition, abundance, feeding behavior, and size distribution of scavenging fish in the NE Atlantic at depths $>2000 \mathrm{~m}$ (Armstrong et al. 1992, Priede et al. 1994, King et al. 2006). 
While attention in scavenger studies has focused on the deeper end of continental margins, limited data are available for shallower areas and for invertebrates. Scavenging represents an important foraging strategy for many animals living at shelf and slope depths (Drazen et al. 2001, Yau et al. 2002, Collins et al. 2005, Yeh \& Drazen 2009) yet ecological data on scavenging communities from these regions of the world's continental margins remain sparse. Several commercially exploited scavenging species inhabit this depth range, such as the red king crab Paralithodes camtchaticus, Patagonian toothfish Dissostichus eleginoides, and Atlantic hagfish Myxine glutinosa. As fisheries extend further offshore into deeper water (Morato et al. 2006) scavenging species are likely to become increasingly exploited. An improved understanding of scavenger ecology and abundance at these depths is warranted, not only because of the current lack of existing data, but also to help guide management of future potential deep-sea stocks that are especially susceptible to overfishing (Devine et al. 2006).

Baited cameras offer an alternative method of estimating fish abundance to the traditional metric of trawl sampling. This approach may be advantageous when the latter is not possible due to bottom terrain, limitations in shiptime, or when non-extractive, low-impact sampling is desired. Priede et al. (1990) proposed a model that estimates fish density (ind. $\mathrm{km}^{-2}$ ) at a camera deployment based on the current speed $\left(V_{\mathrm{c}}\right)$, swimming speed of the fish $\left(V_{\mathrm{f}}\right)$, and the time of arrival of the first fish after touchdown, or first arrival time $\left(t_{0}\right)$. Since then, estimates of abyssal fish density based on $t_{0}$ data have been widely published (Priede et al. 1994, Yau et al. 2001, King et al. 2006, King \& Priede 2008, Jamieson et al. 2009), however the accuracy of these estimates in comparison to trawl data has only been evaluated on one occasion (Priede \& Merrett 1996). Stock assessment is an integral step in establishing management guidelines for any fishery and can benefit from abundance data gleaned from baited cameras. Before baited camera-derived abundance estimates can be used with confidence, however, the model's accuracy needs to be validated by comparing results with independent methods of density estimation (i.e. towed camera surveys, submersible transects, trawling).

Scavengers in the deep sea rely primarily on olfaction to detect and locate food falls, as evidenced by observations of fish usually arriving from down current (Smith 1985) and by the large brain areas of abyssal fishes dedicated to smell and taste (Wagner 2001). It follows that scavenger response to baited experiments should be influenced by the type of bait being used, which for the most part has consisted of scombroid fishes (Priede et al. 1990, Henriques et al. 2002, Yeh \& Drazen 2009). Barry \& Drazen (2007) made opportunis- tic observations on the effect of introducing macrourid carrion on scavenger behavior when individuals of Coryphaenoides armatus died during caged experiments. Numbers of Pachycara sp. and Benthoctopus sp. increased following the death of caged $C$. armatus (introduction of macrourid carrion), however, the opposite was true for free ranging $C$. armatus whose presence at the experiment was reduced to just a few occurrences. Bait type is very likely to affect both the reaction of scavengers to bait - potentially altering $t_{0}$ derived abundance estimates - and the composition of the scavenging community. This has been the reason for using standardized bait across studies; however, this approach has also precluded an evaluation of the variability in scavenger response based on bait type.

The relationship between size and depth in fishes is a topic that has produced confounding results. Heinke (1913) made early observations in the North Sea of what is now known as the 'bigger-deeper' phenomenon increased fish size with increased depth. Since then studies have both corroborated these findings in the deep sea (Polloni et al. 1979, Macpherson \& Duarte 1991) and found the opposite trend - 'smaller-deeper' (Stefenescu et al. 1992, Moranta et al. 2004). Conflicting results have even been reported for the same species (Antimora rostrata; Collins et al. 2005, King et al. 2006) and from similar regions (NW Mediterranean; Macpherson \& Duarte 1991, Stefenescu et al. 1992). These differences have been attributed to feeding mode, life histories, and sampling methods of the fishes studied (Snelgrove \& Haedrich 1985, Collins et al. 2005, Yeh \& Drazen 2009). Perhaps the only clear result that has emerged is that no single relationship between size and depth prevails across all species, communities, regions, and depth strata. As more information on size-depth distributions is gathered, generalizations of depth related size trends will be become easier to formulate.

Here we present baited camera observations in conjunction with data collected with other methods of sampling to improve our understanding of scavenger ecology across a wide range of taxa spanning the entire California slope. Our objectives were (1) to describe the megafaunal scavenging assemblage from 100 to $3000 \mathrm{~m}$ in terms of composition, vertical distribution, and relative abundance, (2) to compare camera and trawl derived estimates of fish density, (3) to investigate size-depth relationships in scavenging fishes, and (4) to examine the effect of using macrourid bait on scavenging behavior.

\section{MATERIALS AND METHODS}

Data collection. The deep-sea scavenging community of Monterey Bay off the central coast of California, 
USA (Fig. 1), was studied using a free-vehicle, timelapse camera following the design presented by Yeh \& Drazen (2009). This system utilizes a 4.0 Mpx digital still camera and strobe (Scorpio Plus, Insite Pacific) suspended $2 \mathrm{~m}$ above the seafloor to photograph animals attracted to bait. Bait in this study consisted of one 1 to $2 \mathrm{~kg}$ fish (Chanos chanos) per deployment and was chosen based on availability and size homogeneity. All baits were defrosted and scored prior to deployment to enhance dispersal of the odor plume. Images were taken at 2 min intervals to maximize the amount of data that could be collected in a $24 \mathrm{~h}$ period. A current meter (Aquadopp, Nortek) mounted to the instrument frame $2 \mathrm{~m}$ above the seafloor recorded pressure, temperature, and current velocity at $1 \mathrm{~min}$ intervals.

Individuals were recognized as scavengers based on their observed consumption of bait (Britton \& Morton 1994). Scavengers were identified to the lowest taxonomic level based on diagnostic morphological characteristics using standard keys and texts in conjunction with consultation with taxonomic specialists. For each deployment, the first arrival time, $t_{0}$ (the time required for the first individual to arrive at bait after vehicle touchdown), and peak abundance, $n_{\max }$ (maximum number of a species observed in any single image throughout the deployment), were recorded for all scavenging species present. The percentage of frames in which at least 1 individual was observed, \% frame, was determined for Coryphaenoides armatus at all $3000 \mathrm{~m}$ deployments.
In addition to camera imagery, data were incorporated from other methods of sampling that were being conducted simultaneously during the same cruises for related projects. These included various baited hook sets and bottom trawling. Baited hook sets were not quantitative but did provide presence/absence and size data. An otter trawl (estimated door spread $6.1 \mathrm{~m}$, mesh size $2.5 \mathrm{~cm}$ ) was used at all depths and a beam trawl (mouth width $2.1 \mathrm{~m}$, height $0.8 \mathrm{~m}$, mesh size $2.5 \mathrm{~cm}$ ) was used for some tows $\geq 2000 \mathrm{~m}$. Both gears were fished on a single warp and rigged with a pinger (Benthos) $70 \mathrm{~m}$ from the bridle to monitor net contact with the seafloor and 1 or 2 (depending on scope) $43 \mathrm{~cm}$ floats between the net and the pinger to suspend the trawl wire off the bottom. Trawl durations ranged from 15 to 60 min and depths were treated as median depth during the time that the trawl was contacting the seafloor during each haul. Animals caught via these sampling efforts provided voucher specimens to corroborate identifications designated from analysis of camera data and also provided the majority of length measurements for size analyses.

Size analysis. Size analysis of scavenging species Anoplopoma fimbria, Antimora microlepis, Albatrossia pectoralis, and Coryphaenoides acrolepis was performed using measurements obtained from individuals caught via trawls and baited hooks in addition to a few image-derived size estimates from camera data when available. These species were chosen because there were relatively large numbers of measurements and

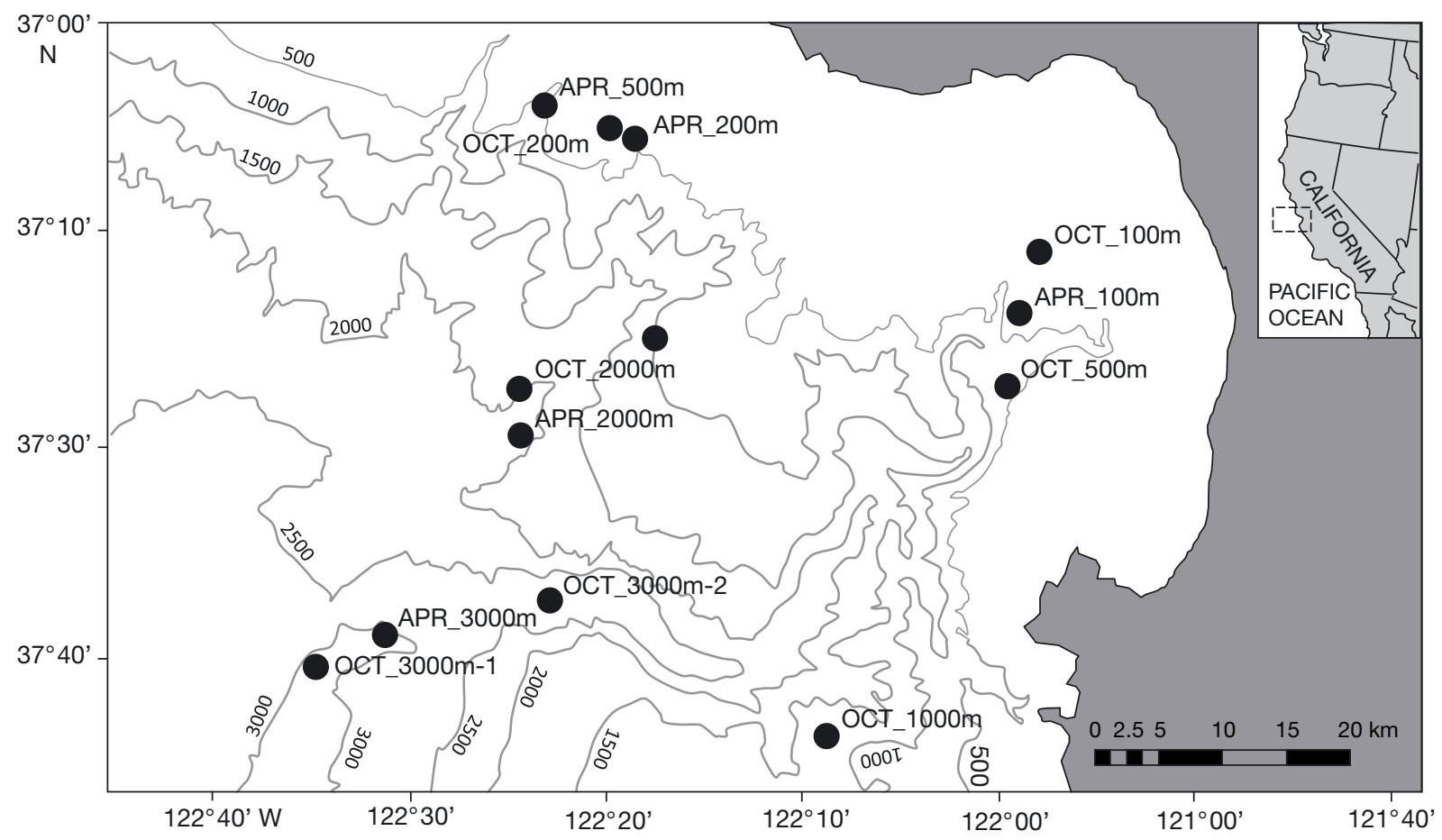

Fig. 1. Baited-camera deployment sites in Monterey Bay, California, USA 
because each species spanned at least 3 depths sampled during the study, thus maximizing the vertical extent of the analysis. Total length (TL) was measured for A. microlepis while fork length (FL) was measured for A. fimbria (due to forked caudal fin in this species) and pre-anal fin length (PAFL) was measured for A. pectoralis, and C. acrolepis (due to broken or incomplete caudal fins found in many individuals of these species). When possible, individuals recorded from camera observations were measured using image analysis software (ImageJ 1.38x). Details of this procedure follow Yeh \& Drazen (2009) and have shown percent error of $\pm 3.5 \%$. A simple linear regression (Statistica v7) was applied to these data to determine significance of the relationship between fish size and depth.

Abundance estimates. Fish densities for Antimora microlepis and Coryphaenoides armatus (ind. $\mathrm{km}^{-2}$ ) were estimated using 2 independent methods, one based on trawl data and the other on camera data $\left(t_{0}\right)$ using the model proposed by Priede \& Merrett (1996). Camera-based estimates utilized $t_{0}$ information in the following formula (Priede \& Merrett 1996):

$$
N\left(\text { ind. } \mathrm{km}^{-2}\right)=\frac{0.3849\left(V_{\mathrm{f}}^{-1}+V_{\mathrm{w}}^{-1}\right)^{2}}{t_{0}^{2}}
$$

where $V_{\mathrm{f}}\left(\mathrm{m} \mathrm{s}^{-1}\right)$ is the swimming velocity of the fish and $V_{\mathrm{w}}\left(\mathrm{m} \mathrm{s}^{-1}\right)$ is the current velocity averaged over the first $30 \mathrm{~min}$ of each deployment. Measured $V_{\mathrm{f}}$ for C. armatus range from 0.0262 to $0.077 \mathrm{~m} \mathrm{~s}^{-1}$ depending on location and time of year (Priede 1994, Henriques et al. 2002). A $V_{\mathrm{f}}$ of $0.0692 \mathrm{~m} \mathrm{~s}^{-1}$ obtained from the northeast Pacific in October was used in this study because this estimate was most appropriate for our data (Priede et al. 1994). Due to the lack of available $V_{\mathrm{f}}$ data for A. microlepis, the measured $V_{\mathrm{f}}$ for its congener Anti- mora rostrata of $0.213 \mathrm{~m} \mathrm{~s}^{-1}$ (Collins et al. 1999) was used. These animals are morphologically very similar, differing only by close counts of gill filaments (Small 1981) and can be expected to have similar swimming velocities. Swimming speeds for other taxa were not available and could not be estimated in this study. Trawl and camera based density estimates from similar depths were compared using correlation analysis (Statistica v7).

\section{RESULTS}

During 2 cruises in April and October of 2009 in Monterey Bay, 13 camera deployments were conducted California (Fig. 1). Deployment depth ranged from 105 to $3144 \mathrm{~m}$, targeting 7 discrete depths: 100, 200, 500, 1000, 2000, and $3000 \mathrm{~m}$. Camera bottom time ranged from 15:20 to 27:46 (hh:mm), with the average duration of data collection lasting 16:54 ( $\pm 2: 01)$. Deployment information is summarized in Table 1. Additional data from 42 trawls, 3 long line, and 2 baited trap deployments were used to augment size analyses and to survey the non-scavenging fish fauna.

\section{Community composition and abundance}

Based on observations of attraction to and consumption of bait, 25 taxa were identified as scavengers from photographic data. Identification of all scavenging fish species were confirmed with voucher specimens obtained via other methods of sampling. Multiple species of the zoarcid genus Pachycara were identified from trawls (Pachycara sp., P. bulbiceps, P. gymninium, and $P$. lepinium); however it was not possible to apply the same morphological scrutiny to individuals of this

Table 1. Baited camera deployment information. Current speed $\left(V_{\mathrm{c}}\right)$ was averaged over the first 30 min of each deployment

\begin{tabular}{|c|c|c|c|c|c|c|c|}
\hline Deployment & Latitude ${ }^{\circ} \mathrm{N}$ & Longitude ${ }^{\circ} \mathrm{W}$ & $\begin{array}{l}\text { Deploy date } \\
\text { (dd.mm.yyyy) }\end{array}$ & $\begin{array}{l}\text { Deploy time } \\
\text { (hh:mm) }\end{array}$ & $\begin{array}{l}\text { Duration } \\
\text { (hh:mm) }\end{array}$ & $\begin{array}{l}\text { Depth } \\
\text { (m) }\end{array}$ & $\begin{array}{c}V_{\mathrm{c}} \\
\left(\mathrm{m} \mathrm{s}^{-1}\right)\end{array}$ \\
\hline APR_100m & 3648.080 & 12158.454 & 04.04 .2009 & $14: 17$ & $15: 20$ & 105 & 0.056 \\
\hline APR_200m & 3655.457 & 12218.227 & 05.04 .2009 & $12: 47$ & $19: 18$ & 209 & 0.065 \\
\hline APR_500m & 3656.633 & 12222.807 & 07.04 .2009 & $18: 36$ & $15: 10$ & 587 & 0.020 \\
\hline APR_1000m & 3647.187 & 12217.254 & 08.04 .2009 & $20: 18$ & $15: 48$ & 1010 & 0.094 \\
\hline APR_2000m & 3643.144 & 12224.100 & 10.04 .2009 & $13: 44$ & $24: 36$ & 2097 & 0.032 \\
\hline APR_3000m & 3634.923 & 12231.196 & 11.04 .2009 & $22: 14$ & $18: 54$ & 3055 & 0.071 \\
\hline OCT_100m & 3650.610 & 12157.452 & 03.10 .2009 & $06: 45$ & $23: 28$ & 109 & 0.045 \\
\hline OCT_200m & 3655.812 & 12219.418 & 30.09 .2009 & $10: 41$ & $20: 56$ & 215 & 0.076 \\
\hline OCT_500m & 3645.088 & 12159.117 & 11.10 .2009 & $16: 51$ & $20: 18$ & 578 & 0.060 \\
\hline OCT_1000m & 3630.654 & 12208.525 & 10.10 .2009 & $16: 11$ & $18: 44$ & 1116 & 0.056 \\
\hline OCT_2000m & 3645.033 & 12224.195 & 04.10 .2009 & $13: 20$ & $15: 46$ & 1967 & 0.054 \\
\hline OCT_3000m-1 & 3633.689 & 12234.684 & 06.10 .2009 & 08:08 & $27: 46$ & 3144 & 0.045 \\
\hline OCT_3000m-2 & 3636.413 & 12222.786 & 09.10 .2009 & $10: 45$ & $21: 20$ & 2869 & 0.036 \\
\hline
\end{tabular}


genus in photographic data when trying to distinguish species. As a result, all individuals of Pachycara were treated as Pachycara spp. Similarily, photographic distinction between Coryphaenoides acrolepis and its congener $C$. filifer was not possible in most instances, so these species were treated as Coryphaenoides spp. Invertebrate identifications should remain tentative with the exception of Neolithodes diomedea, Cancer magister, Cancer productus, Chionoecetes tanneri, Rathbunaster californicus, and Benthoctopus sp. for which vouchers were obtained.

Roughly half of the scavenger assemblage was comprised of fish (12 taxa) while the other half consisted of invertebrates, most of which were decapod crabs (8 species). Other invertebrates included cephalopods, gastropods, and one echinoderm. Invertebrates dominated species richness from 100 to $200 \mathrm{~m}$, while scavenger composition shifted to a fish dominated assemblage at depths $>500 \mathrm{~m}$. The Macrouridae was the most speciose fish family, with Albatrossia pectoralis, Coryphaenoides acrolepis, C. armatus, and C. filifer collectively spanning a range of $2000 \mathrm{~m}$ and accounting for $50 \%$ of all teleost taxa observed. The most abundant fish species observed were the hagfish Eptatretus deani and E. stouti, which reached peak abundances of 52 and 19 individuals, respectively (Table 2). The morid Antimora microlepis occupied the largest vertical range of any single species with a minimum depth of occurrence of $1000 \mathrm{~m}$ and a maximum depth of occurrence (max depth) of $3000 \mathrm{~m}$. The observation of the broad skate Amblyraja badia during deployment OCT_3000m-2 extends the known max depth of this species from 2322 to $2869 \mathrm{~m}$ (Ormseth et al. 2008) and adds to the very few records of elasmobranchs found deeper than $2500 \mathrm{~m}$ (Priede et al. 2006). Decapod crabs accounted for the largest portion of the scavenger assemblage with 8 species, or $32 \%$ of the all scavenging taxa observed. Crabs were not only speciose, but highly abundant (Paralomis manningii and P. verrilli, $n_{\max }=24$ and 20 respectively, Table 2 ) and distributed along the entire slope ( $\geq 1 \mathrm{crab}$ species present at every target depth).

\section{Scavenger size}

FL for Anoplopoma fimbria $(\mathrm{n}=91)$, TL for Antimora microlepis $(\mathrm{n}=149)$, and PAFL length for Albatrossia pectoralis $(\mathrm{n}=28)$ and Coryphaenoides acrolepis $(\mathrm{n}=$ 727) are plotted against depth of capture/observation in Fig. 2. From camera imagery, 21 additional TL measurements were obtained for $A$. microlepis. Significant linear regressions $(\mathrm{p}<0.05$ between length and depth were found for all species. Anoplopoma fimbria, Antimora microlepis, and A. pectoralis increased in size with increasing depth (slope $=0.048,0.011,0.011$,

Table 2. Scavenger peak abundance $\left(n_{\max }\right)$. ELAS: elasmobranch, MYX: myxiniform, OTHER: other invertebrates

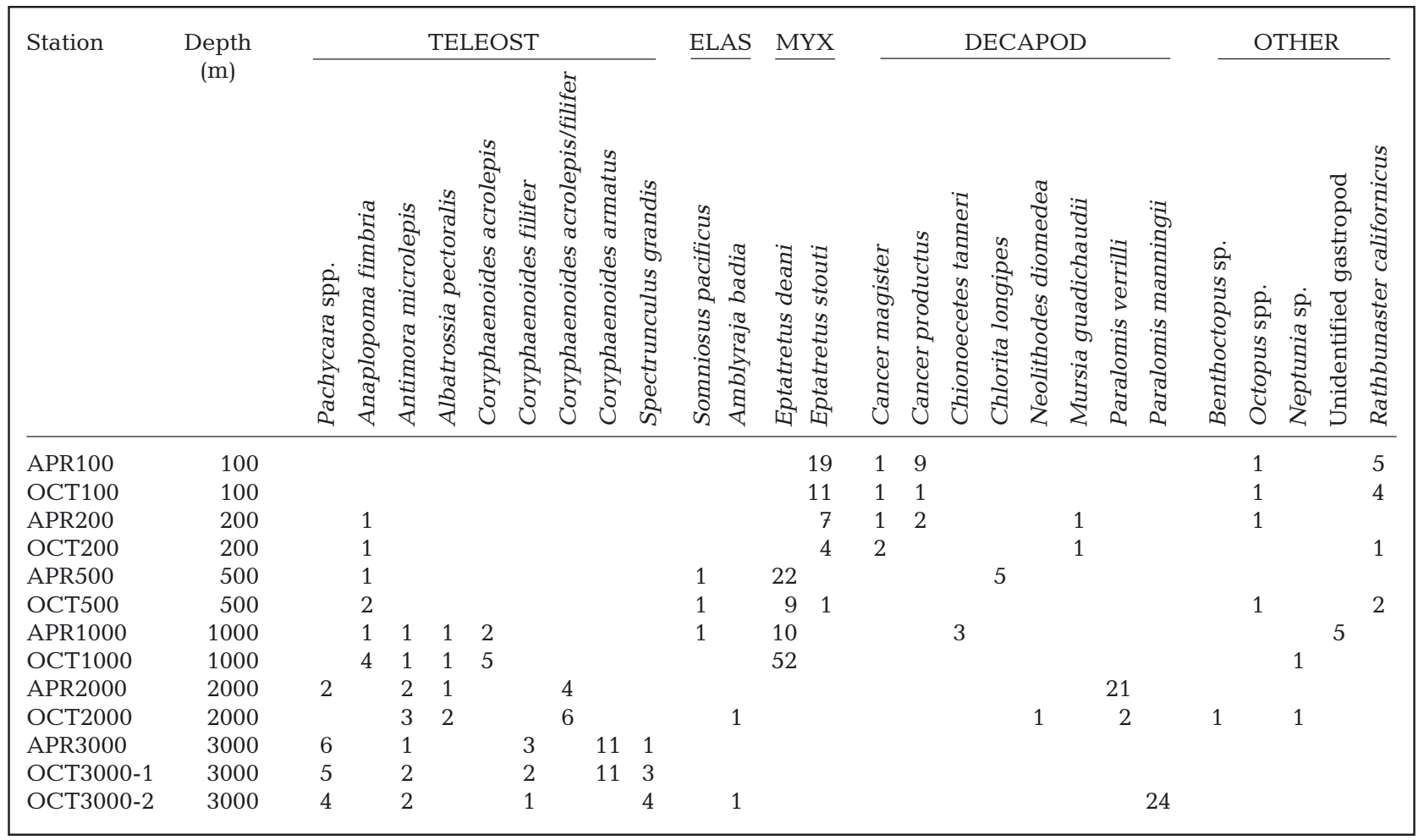


respectively) while $C$. acrolepis showed a slight but significant decline with depth (slope $=-0.005$ ).

\section{Abundance estimation}

Fish densities were estimated independently using trawl data and $t_{0}$ data for 2 fish species, Antimora microlepis and Coryphaenoides armatus (Table 3). First arrival time derived estimates were based on data from single deployments due to small sample size, while trawl derived estimates represented data averaged across multiple hauls ( $\mathrm{n}=2$ to 4 ) conducted at similar depths and dates. Density estimates were compared between both methods and no significant correlation was found (Fig. 3). Within methods, estimates generally showed consistency and agreed well with each other for a given species and depth. For example, camera estimates for A. microlepis at $2000 \mathrm{~m}$ in April and October (1412 and 1615 ind. $\mathrm{km}^{-2}$, respectively) agreed well with each other as did trawl estimates for C. armatus at $3000 \mathrm{~m}$ in April and October (720 and 801 ind. $\mathrm{km}^{-2}$, respectively).

\section{Scavenging as a function of depth}

The frequency of scavenging as a feeding mode was evaluated by comparing the number of scavenging fish species to the total number of fish species for each target depth. Scavenging fish species were designated as such based on camera observations. The total number of fish species was calculated as the cumulative sum of all distinct species observed across the suite of sampling methods used in this study. The resulting ratio depicts the percentage of the fish taxa that is com-

Table 3. Antimora microlepis and Coryphaeonoides armatus. Comparison of estimated fish density (ind. $\mathrm{km}^{-2}$ ) based on camera and trawl data. Camera estimates utilize first arrival $\left(t_{0}\right)$ data from single deployments while trawl estimates display averages $\pm \mathrm{SD}$, number of samples in parentheses

\begin{tabular}{|c|c|c|c|}
\hline & \multirow{2}{*}{$\begin{array}{c}t_{0} \\
(\min )\end{array}$} & \multicolumn{2}{|c|}{ Fish density (ind. $\mathrm{km}^{-2}$ ) } \\
\hline & & Camera & $\begin{array}{c}\text { Trawl } \\
\text { (no. samples) }\end{array}$ \\
\hline \multicolumn{4}{|c|}{ Antimora microlepis } \\
\hline APR 1000 & $(862)$ & 0 & $395 \pm 287$ \\
\hline OCT 1000 & (124) & 4 & $810 \pm 326(4)$ \\
\hline APR 2000 & (10) & 1412 & $418 \pm 214$ \\
\hline OCT 2000 & (6) & 1615 & $477 \pm 344$ \\
\hline APR 3000 & (36) & 29 & $0 \pm 0(2)$ \\
\hline OCT 3000 & (40) & 48 & $0 \pm 0(3)$ \\
\hline \multicolumn{4}{|c|}{ Coryphaenoides armatus } \\
\hline APR 3000 & (20) & 217 & $720 \pm 727$ \\
\hline OCT 3000 & (14) & 726 & $801 \pm 836$ \\
\hline
\end{tabular}
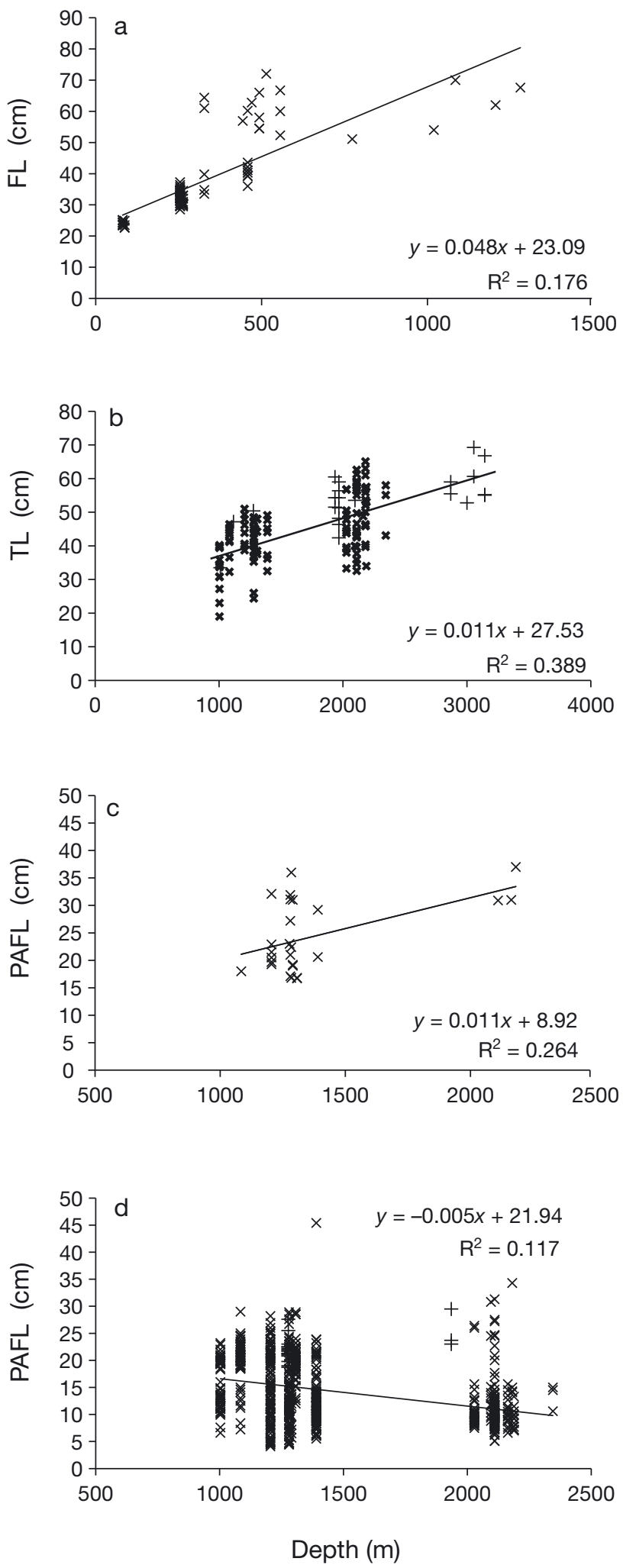

Fig. 2. Fish length $(\mathrm{cm})$ vs. depth of capture or observation for (a) Anoplopoma fimbria, (b) Antimora microlepis, (c) Albatrossia pectoralis, and (d) Coryphaenoides acrolepis. $\times$ : trawl caught; +: baited individuals; FL: fork length; TL: total length; PAFL: pre-anal fin length 


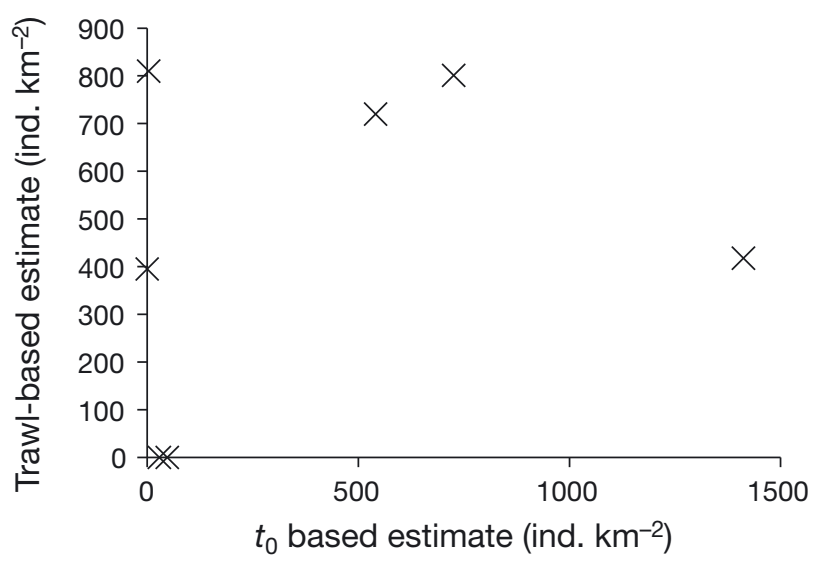

Fig. 3. Estimated fish densities, trawls vs. camera

prised of scavengers (Fig. 4). A steady increase from shelf to abyssal depths in the ratio between the number of scavenging fish species vs. non-scavenging fish species is apparent. At $100 \mathrm{~m}$, only $2 \%$ of all fishes were scavengers, while at $3000 \mathrm{~m}, 46 \%$ of all fishes were scavengers. In general, a decline was seen in the total number of fish species found with increasing depth. When scavenging fish species were considered separately, the opposite trend was displayed-scavenging fish species richness increased with increasing depth.

\section{Macrourid bait and scavenging behavior}

Coryphaenoides armatus was found in high abundances at $3000 \mathrm{~m}$ in this study. Camera data (deployments APR_3000m and OCT_3000m-1, Table 2) and trawl data (Table 3) from different times in the year demonstrate the omnipresence of this cosmopolitan scavenger in Monterey Bay. During baited-camera deployment OCT_3000m-2, bait was switched from the standard bait in this study, Chanos chanos $(\sim 2 \mathrm{~kg})$, to one whole $C$. armatus of similar size. A complete absence of C. armatus was observed during this $21 \mathrm{~h}$ deployment (Fig. 5a). Both deployments using standard bait (Fig. 5b, c) exhibited high peak abundances, short first arrival times, and high percentages of frames with at least 1 individual in the field of view (Table 4). The 3 other non-macrourid scavenging fish taxa present at $3000 \mathrm{~m}$ deployments using standard bait appeared to be unaffected in terms of $n_{\max }$ (Table 2) by the switch to macrourid bait. Similarily, no trends were detectable in $t_{0}$ for these species between bait types (A. microlepis 36 and 40 vs. $22 \mathrm{~min}_{\text {; }}$ S. grandis 522 and

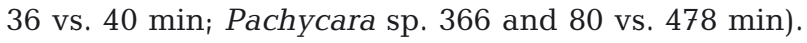
However, C. filifer, the other macrourid at this depth did have a lower $n_{\max }$ (Table 2) and a higher first arrival time (114 min) when macrourid bait was used compared to the other $3000 \mathrm{~m}$ deployments (40 and 28 min). Paralomis manningii was only found at OCT_3000m-2 during this study and in high abundance $\left(n_{\max }=24\right)$.

\section{DISCUSSION}

\section{Validity of abundance estimates}

Our comparison of camera- and trawl-derived abundance estimates showed no correlation (Fig. 3). It is possible that the swimming speeds used here do not accurately reflect actual speeds of fishes in this study. To address this possibility, the full range of measured $V_{\mathrm{f}} \mathrm{s}$ for Coryphaenoides armatus was considered (data

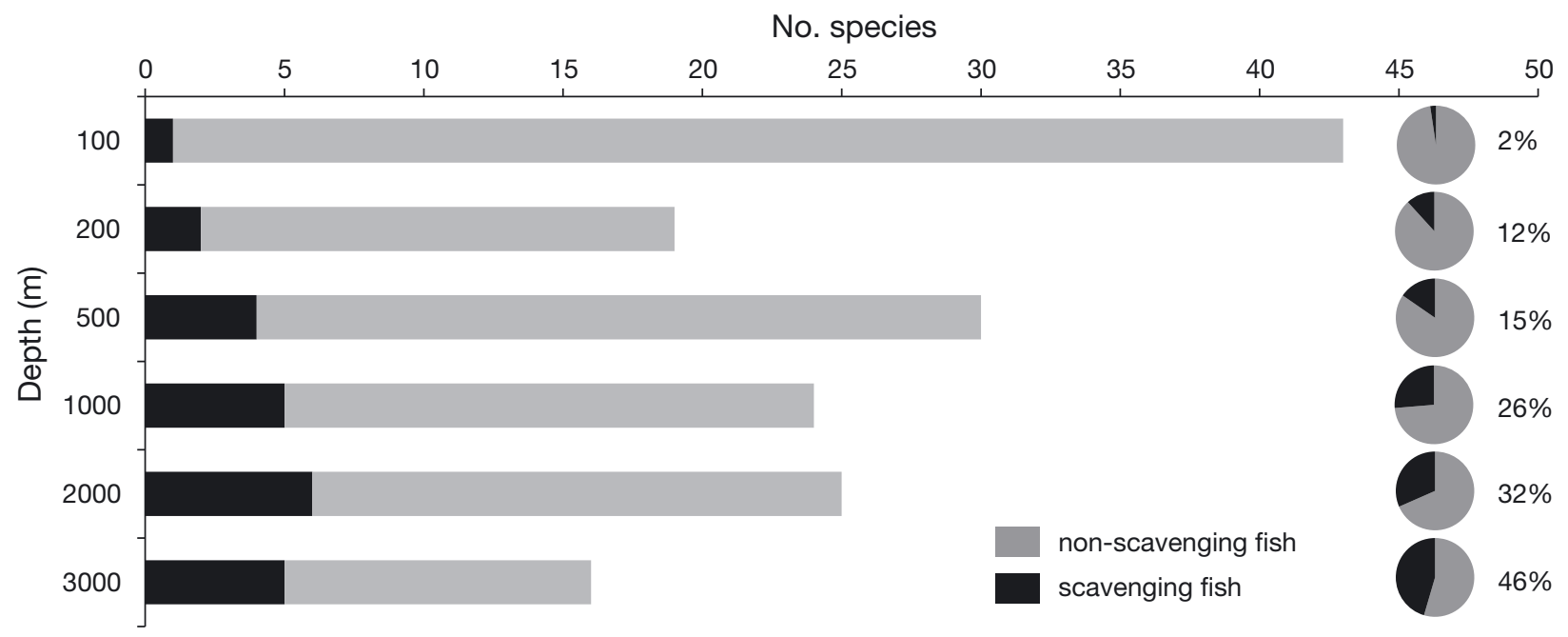

Fig. 4. Numbers of fish species. Scavenging (grey) vs. non-scavenging species (black) for targeted depths 

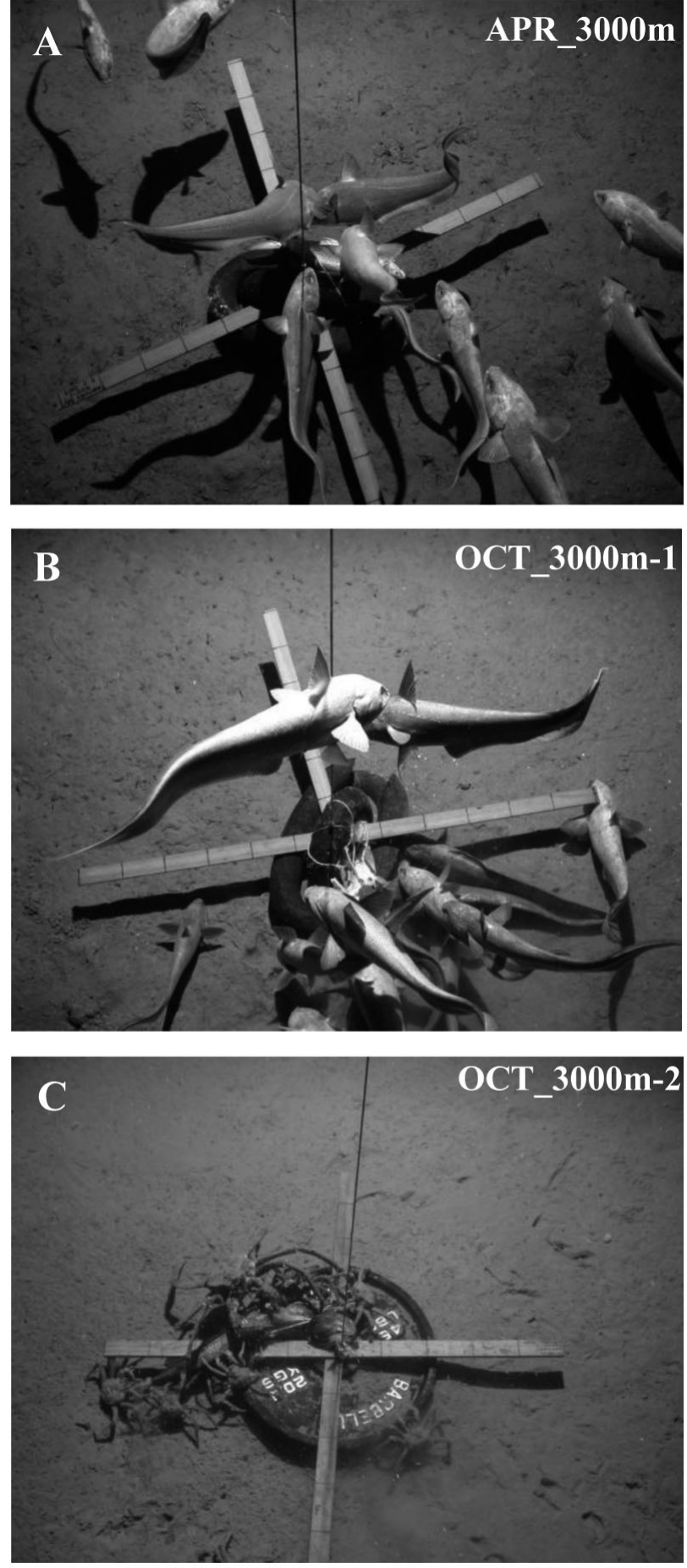

Fig. 5. Coryphaenoides armatus. Images from $3000 \mathrm{~m}$ camera deployments at time of peak abundance $\left(n_{\max }\right)$ using $(\mathrm{A}, \mathrm{B})$ Chanos chanos as bait and (C) C. armatus as bait

not presented) but still no correlation was found. This analysis was hindered by sample size; for each depth and time of year analyzed, data from only single camera deployments were available to compare to the trawl data. Additionally, trawl-derived fish density
Table 4. Coryphaeonides armatus. Abundance data for $3000 \mathrm{~m}$ deployments. $n_{\max }$ : peak abundance; \%frames: percentage of frames in which at least 1 individual was observed; $t_{0}$ : time of first arrival; na: not applicable

\begin{tabular}{|lccc|}
\hline & $\begin{array}{c}n_{\max } \\
\text { (ind.) }\end{array}$ & $\begin{array}{c}\%_{\text {frames }} \\
(\%)\end{array}$ & $\begin{array}{c}t_{0} \\
(\mathrm{~min})\end{array}$ \\
\hline APR_3000m & 11 & 50 & 12 \\
OCT_3000m-1 & 12 & 83 & 14 \\
OCT_3000m-2 & 0 & 0 & na \\
\hline
\end{tabular}

showed high variability for temporally and spatially similar hauls as evidenced by standard deviations on the same order of magnitude as the averages themselves (Table 3). However, given that no other statistical comparison of these types of estimates exists, our efforts offer useful information in evaluating a general model that has rarely been tested. The results do demonstrate precision within methods, evidenced by consistent and reproducible results.

Priede \& Merrett (1996) did find correlation between baited camera and trawl methods of density estimation, however, in their statistical treatment of the data they compared the quantity $t_{0}^{-2}$ against trawl data as opposed to comparing the output of the model itself to the trawl data. We found no such correlation (data not shown). This approach eliminates variation that may have arisen due to differences in current velocity, which is an inherent parameter of their model. Furthermore, trawl and camera data in their study were averaged over a large latitudinal range (up to $18^{\circ}$ ), and homogeneity in abundance is unlikely to hold over such a large area. When these considerations are taken into account, disagreement between studies is explicable. Farnsworth et al. (2007) performed an in depth evaluation of abundance estimation based on first arrival time and concluded this method is highly uncertain, but this finding was based on a purely theoretical approach. Our results support their finding with empirical data.

\section{Scavenging behavior and depth}

While depth-related patterns in the size, abundance, and vertical zonation of scavengers have received significant attention, the prevalence of scavenging behavior itself with respect to depth has rarely been documented. Multiple collection methods employed in this study allowed for comprehensive sampling of the demersal fish fauna of the California slope as well as the ability to discern between scavenging and nonscavenging taxa. The progressive transition of 2 to $46 \%$ scavengers observed from 100 to 3000 m (Fig. 4) 
suggests an increasing importance of carrion in the diets of demersal fishes and a shift to an opportunistic foraging strategy at deeper portions of continental margins. This finding contrasts with observations in the NE Atlantic where Priede et al. (2010) found scavenging fish to comprise a constant proportion of the fish fauna $(22.7 \%$ ) from 240 to $4965 \mathrm{~m}$. This result was an average across depths. If the data presented in Fig. 4 are averaged, the resulting value of $22 \%$ would be very close to that presented by Priede et al (2010). It is interesting to note that at depths $<1000 \mathrm{~m}$, the data in Priede et al. (2010) yield percentages of $<10 \%$, similar to our own findings. The real difference in trends is that the proportion of scavengers below $1000 \mathrm{~m}$ change very little with depth in the North Atlantic but the proportion increases in our results. The fauna in the Priede et al. (2010) study come from a larger sampling effort than ours. It is possible that additional species of both scavenging and non-scavenging taxa would be sampled off California with more deployments, thus altering our results.

A depth-related increase in the proportion of scavenging fish follows trends in food availability. Many demersal fishes consume benthic and demersal invertebrates (Pearcy \& Amber 1974, Macpherson \& Roel 1987, Takahashi \& Iwami 1997, Drazen et al. 2001). Benthic biomass and abundance have been found to decline exponentially with depth (Rowe et al. 1974, Gage \& Tyler 1985, Lampitt et al. 1986) along the continental slopes of many regions, and as a result food supply is diminished for animals that feed on the benthos. Demersal fish occupying shelf and upper slope depths also consume large proportions of vertically migrating zooplankton and micronekton (Mauchline \& Gordon 1991, Drazen et al. 2001, Yamamura \& Inada 2001, Chae et al. 2008). With increasing distance from shore along continental margins, vertical migrators become less available as a source of prey as water depth exceeds the maximum depth of the deep scattering layer. With limited alternative food sources, animals may broaden their trophic strategies and adopt scavenging to at least partially fulfill their energetic demands. The principal nutritional source for macrourids on the NE Pacific abyssal plain has been suggested to be carrion (Drazen et al. 2008, 2009), supporting this line of reasoning.

\section{Size trends with depth}

Our findings of 'bigger-deeper' trends for Albatrossia pectoralis, Anoplopoma fimbria, and Antimora microlepis but not for Coryphaenoides acrolepis reinforce the notion that size-depth trends should be evaluated on a species by species basis. The 'bigger- deeper' trend has been shown for Anoplopoma fimbria in previous studies and is well established for this species. Results from groundfish surveys (Lauth 1999) show this trend independently for males and females and for both sexes combined. Temporal stability has been demonstrated for 2 decades (1988 to present) and for multiple regions of the US west coast (Lauth 1999, Jacobson et al. 2001). Likewise, A. microlepis has been shown to follow the 'bigger-deeper' trend in the Northwest Pacific off the Kamchatka peninsula, where individuals increased in both TL and weight from depths of 200 to $1700 \mathrm{~m}$ (Orlov \& Abramov 2002 and references within). Its closely related congener from the Atlantic, Antimora rostrata, has also displayed the same trend (Collins et al. 2005). For A. pectoralis, the 'biggerdeeper' trend has also been reported in the Kuril Islands (Orlov \& Tokranov 2008) but in the Gulf of Alaska and eastern Bering Sea males show no size difference with depth and females are smaller at greater depths (Clausen 2008). The reasons for the differences between California and the Bering Sea are unclear. It seems logical that the trends in the Bering Sea are related to reproduction but the regional differences in the patterns might also be related to differing temperature profiles.

In contrast to these species, Coryphaenoides acrolepis displayed a weak decrease in size with increasing water depth $\left(\mathrm{m}=-0.005, \mathrm{R}^{2}=0.117\right.$; Fig. 2). Size decrease with depth has been reported for individual species (Macpherson \& Duarte 1991, Yeh \& Drazen 2009) and for fish assemblages as a whole (Stefenescu et al. 1992). Whether the results presented here are truly evidence of a 'smaller-deeper' trend is questionable. The slightly negative slope may be a result of net avoidance of this species at greater depths or other unexplained sampling biases. What is undeniable is the absence of a 'bigger-deeper' trend for this species. The lack of any size-depth relation was also noted for C. acrolepis collected off Oregon (Stein \& Pearcy 1982).

'Bigger-deeper' phenomena have been attributed to migration to deeper water during ontogeny (Jacobson et al. 2001), but reasons for why this would be evolutionary favorable remain unclear. Macpherson \& Duarte (1991) proposed that ontogenetic migration would be advantageous because deeper living animals would have lower metabolic rates and increased longevity due to depressed temperatures, these depressed temperatures being intolerable or lethal to smaller, younger individuals. However, 'biggerdeeper' trends have been demonstrated in high latitudes where temperature gradients are small and thermoclines not pronounced (Orlov \& Abramov 2002 and references within). Collins et al. (2005) surmised that larger size is required at greater depths only in scav- 
enging fishes to permit greater swimming speeds and lower metabolic rates to facilitate foraging on the carrion of food falls, which become more sporadic with increasing depth. All the species we examined are scavengers as evidenced from baited-camera observations, even C. acrolepis which did not exhibit the bigger-deeper pattern. Yet, 'bigger-deeper' trends have been shown for the flatfish Microstomus pacificus and rockfish Sebastalobus alascanus (Jacobson \& Hunter 1993, Jacobson \& Vetter 1996), both of which were abundant in the study area and in the trawls but were not found to scavenge based on camera observations. Foraging mode does not appear to be as important a driver of size-depth patterns as it is in the North Atlantic (Collins et al. 2005). Instead, off California there is an oxygen minimum zone from $~ 600$ to $1000 \mathrm{~m}$ (Levin 2003) which may alter patterns or curtail others in some species. For instance the ontogenetic migration in dover sole has been attributed to adults finding a habitat with low predation pressure (Hunter et al. 1990). It seems, then, that size-depth trends may not be explained by a single theory and perhaps a combination of ecological and physiological drivers are at play which vary regionally.

\section{Macrourid aversion to conspecific bait}

Coryphaenoides armatus were not attracted to the camera when a conspecific was used as bait. The presence of $C$. armatus in high numbers at camera deployments using standard baits (APR_3000m and OCT $3000 \mathrm{~m}$ ) and in trawl catches in the area (Table 4), suggests that its absence is not coincidental or the result of a lack of animals in the study area. It is possible that differences in tissue composition and biochemistry between bait types vary their resulting odor's detectability or attractiveness. Antimora microlepis, Pachycara spp., and Spectrunculus grandis all reached $n_{\max }$ or near maximum values found in this study (Table 2) when macrourid bait was used, implying odor plume 'strength' was not substantially reduced between bait types. For $C$. armatus it is unlikely that diminished detection ability for macrourid bait caused its absence. This species has demonstrated attraction to a wide range of bait from cetacean carcasses (Kemp et al. 2006) to spinach (Jeffreys et al. 2010), the latter suggesting an acute sense of olfaction in this species which would not likely preclude the odor plumes of dead macrourids. Lampitt et al. (1983) used C. armatus as bait on the North Atlantic abyssal plain and noted very few rattails but many lysianassid amphipods and liparid fishes. Barry \& Drazen (2007) observed similar aversion of $C$. armatus to a dead conspecific and hypothesized that macrourids avoid dead congeners or conspecifics because they may indicate dangerous conditions. It is also interesting that $C$. filifer, the other macrourid observed at $3000 \mathrm{~m}$, had a marginally lower $n_{\max }$ and higher first arrival time when C. armatus was used as bait. This species was never present in large numbers at bait but it is possible that the odor of a congeneric resulting in some aversion. Our results strengthen this idea and suggest that more experiments should be conducted which evaluate the response of scavengers to various types of bait.

Other scavengers observed at $3000 \mathrm{~m}$ appeared unaffected by the bait switch with the exception of the lithodid crab, Paramolis manningii, which was observed only at macrourid bait. Crabs in general displayed patchiness in this study (Table 2) and were not consistently caught in trawls (J. C. Drazen unpubl. data), which could explain these results. However, it is also possible that the crabs are normally deterred by the presence of more active scavenging rattails either due to competition or predation.

Nearly 40 yr have passed since the first baited camera experiments were performed off southern California. We compared fish density estimates derived from baited camera data to those derived from trawl data with statistical rigor and no correlation was found. Baited cameras are certainly useful tools in examining scavenger ecology - many animals which avoid trawls are only observed remotely. However, further investigation is recommended before abundance estimates from this technique can be interpreted with confidence. From the community perspective, our results show changes in the dominant scavengers with depth from crabs and hagfishes to macrourids and other fishes at greater depths. The proportion of fishes that were scavengers increased from 2 to $46 \%$ with depth unlike data for the North Atlantic, in which the proportion of scavengers changed little with depth. In addition, our findings have contributed more information to the size-depth conundrum in fish. Contrary to recent hypotheses suggesting that 'bigger-deeper' trends are determined by foraging strategy in the North Atlantic, our North Pacific data suggest a global explanation may be more complicated. The basin to basin differences highlight the need to conduct more baited camera studies in other parts of the world so that we can derive a better understanding of scavenger ecology globally. Finally, bait type was shown to affect scavengers differently, with complete avoidance of the odor of conspecifics, highlighting the need to use different bait types to learn more about the behavior and ecology of these species.

Acknowledgements. The authors thank the captain and crew of the RV 'Point Sur' who made field work possible. We also thank S. Ainsley, M. Boyle, N. Condon, J. Friedman, M. Kay, 
D. Kline, C. Laxson, J. Lighten, K. Schmidt, and P. Yancey, who participated in the cruises and whose assistance was very helpful in completing this project. The comments of 3 anonymous reviewers improved the manuscript. This work was funded by NSF grant BioOCE no. 0727135.

\section{LITERATURE CITED}

Armstrong JD, Bagley PM, Priede IG (1992) Photographic and acoustic tracking observations of the behaviour of the grenadier Coryphaenoides (Nematonurus) armatus, the eel Synaphobranchus bathybius, and other abyssal demersal fish in the North Atlantic Ocean. Mar Biol 112: 535-544

Bailey DM, King NJ, Priede IG (2007) Cameras and carcasses: historical and current methods for using artificial food falls to study deep-water animals. Mar Ecol Prog Ser 350: 179-191

Barry JP, Drazen JC (2007) Response of deep-sea scavengers to ocean acidification and the odor from a dead grenadier. Mar Ecol Prog Ser 350:193-207

Britton JC, Morton B (1994) Marine carrion and scavengers. Oceanogr Mar Biol Annu Rev 32:369-434

Chae J, Han C, Lee JH, Hong JS (2008) A short note on a euphausiid, Euphausia pacifica, an important food source to demersal fishes in Uljin area, the eastern coast of Korea. J Environ Biol 29:471-474

Clausen DM (2008) The giant grenadier in Alaska. In: Orlov AM, Iwamoto T (eds) Grenadiers of the world oceans: biology, stock assessment, and fisheries, Vol 63. American Fisheries Society, Maryland, p 413-450

> Collins MA, Priede IG, Bagley P (1999) In situ comparison of activity of two deep-sea scavenging fishes occupying different depth zones. Proc Biol Sci 266:2011-2016

Collins MA, Bailey DM, Ruxton GD, Priede IG (2005) Trends in body size across an environmental gradient: a differential response in scavenging and non-scavenging demersal deep-sea fish. Proc Biol Sci 272:2051-2057

> Devine JA, Baker KD, Haedrich RL (2006) Deep-sea fishes qualify as endangered. Nature 439:29

> Drazen JC, Buckley TW, Hoff GR (2001) The feeding habits of slope dwelling macrourid fishes in the eastern North Pacific. Deep-Sea Res I 48:909-935

> Drazen JC, Popp BN, Choy CA, Smith KL (2008) Bypassing the abyssal food web: macrourid diet in the eastern North Pacific inferred from stomach content and stable isotope analyses. Limnol Oceanogr 53:2644-2654

> Drazen JC, Phleger CF, Guest MA, Nichols PD (2009) Lipid composition and diet inferences in abyssal macrourids of the eastern North Pacific. Mar Ecol Prog Ser 387:1-14

Farnsworth KD, Thygesen UH, Ditlevsen S, King NJ (2007) How to estimate scavenger fish abundance using baited camera data. Mar Ecol Prog Ser 350:223-234

Gage JD, Tyler PA (1991) Deep-sea biology: a natural history of organisms at the deep-sea floor. Cambridge University Press, Cambridge

Heinke F (1913) Investigations on the plaice. I. The plaice fishery and protective regulations. Rapp P-V Reun Comm Int Explor Mer 17:1-153

Henriques C, Priede IG, Bagley PM (2002) Baited camera observations of deep-sea demersal fishesof the northeast Atlantic Ocean at 15-28N off West Africa. Mar Biol 141: 307-314

Hunter JR, Butler J, Kimbrell C, Lynn EA (1990) Bathymetric patterns in size, age, sexual maturity, water content, and caloric density of Dover sole, Microstomus pacificus. CCOFI Rep 31:132-144
Isaacs JD (1969) The nature of oceanic life. Sci Am 221: $146-162$

Isaacs JD, Shwartzlose RA (1975) Active animals of the deepsea floor. Sci Am 233:85-91

Jacobson LD, Brodziak J, Rogers J (2001) Depth distributions and time-varying bottom trawl selectivities for Dover Sole (Microstomus pacificus), sablefish (Anoplopoma fimbria), and thornyheads (Sebastalobus alascanus and S. altivelis) in a commercial fishery. Fish Bull 99:309-327

Jacobson LD, Hunter JR (1993) Bathymetric demography and management of Dover Sole. N Am J Fish Manag 13: $405-420$

Jacobson LD, Vetter RD (1996) Bathymetric demography and niche separation of thornyheads rockfish: Sebastolobus alascanus and Sebastolobus altivelis. Can J Fish Aquat Sci 53:600-609

Jamieson AJ, Fujii T, Solan M, Matsumoto AK, Bagley PM, Priese IG (2009) Liparid and macrourid fishes of the hadal zone: in situ observations of activity and feeding behavior. Proc Biol Sci 276:1037-1045

Kemp KM, Jamieson AJ, Bagley PM, McGrath H, Bailey DM, Collins MA, Priede IG (2006) Consumption of large bathyal food fall, a six month study in the NE Atlantic. Mar Ecol Prog Ser 310:65-76

Jeffreys RM, Lavaleye MSS, Bergman MJN, Duineveld GCA, Witbaard R, Linley T (2010) Deep-sea macrourid fishes scavenge on plant material: evidence from in situ observations. Deep-Sea Res I 57:621-627

King NJ, Priede IG (2008) Coryphaenoides armatus, the Abyssal Grenadier: global distribution, abundance, and ecology as determined by baited landers. Am Fish Soc Symp 63:139-161

King NJ, Bagley PM, Priede IG (2006) Depth zonation and lattitudinal distribution of deep-sea scavenging demersal fishes of the Mid-Atlantic Ridge. Mar Ecol Prog Ser 319: 263-274

Lampitt RS, Merrett NR, Thurston MH (1983) Inter-relations of necrophagous amphipods, a fish, and tidal currents in the deep sea. Mar Biol 74:73-78

> Lampitt RS, Billett DSM, Rice AL (1986) Biomass of invertebrate megabenthos from 500 to $4100 \mathrm{~m}$ in the northeast Atlantic Ocean. Mar Biol 93:69-81

Lauth, RR, Wilkins ME, Raymore Jr PR (1997) Results of trawl surveys of groundfish resources of the West Coast upper continental slope from 1989 to 1993. US Dep Commerce, NOAA Tech Memo NMFS-AFSC-79

Levin LA (2003) Oxygen minimum zone benthos: adaptation and community response to hypoxia. Oceanogr Mar Biol Annu Rev 41:1-45

> Macpherson E, Duarte CM (1991) Bathymetric trends in demersal fish size: is there a general relationship? Mar Ecol Prog Ser 71:103-112

Macpherson E, Roel BA (1987) Trophic relationships in the demersal fish community of Namibia. S Afr J Mar Sci 5: 585-596

> Mauchline J, Gordon JDM (1991) Oceanic pelagic prey of benthopelagic fish in the benthic boundary layer of a marginal oceanic region. Mar Ecol Prog Ser 74:109-115

> Moranta J, Palmer M, Massutí E, Stefanescu C, Morales-Nin B (2004) Body fish size tendencies within and among species in the deep sea of the western Mediterranean. Sci Mar 68(Supp 3):141-152

Morato T, Watson R, Pitcher TJ, Pauly D (2006) Fishing down the deep. Fish Fish 7:24-34

Orlov AM, Abramov AA (2002) New data on flat-nosed hake Antimora microlepis (Moridae) from the northwestern Pacific Ocean. J Ichthyol 42:65-73 
Orlov AM, Tokranov AM (2008) Some ecological and biological features of Giant and Popeye grenadiers in the Pacific waters off the Northern Kuril Islands and Southeastern Kamchatka. In: Orlov AM, Iwamoto T (eds) Grenadiers of the world oceans: biology, stock assessment, and fisheries, Vol 63. American Fisheries Society , Maryland, p 225-260

Ormseth O, Matta B, Hoff J (2008) Bering Sea and Aleutian Island Skates. Section in MPFMC Bering Sea and Aleutian Islands SAFE:1231-1326

Pearcy WG, Ambler JW (1974) Food habits of deep-sea macrourid fishes off the Oregon coast. Deep-Sea Res Oceanogr Abstr 21:745-759

Polloni P, Haedrich R, Rowe G, Clifford CH (1979) The sizedepth relationship in deep ocean animals. Int Rev Gesamten Hydrobiol Hydrograph 64:39-46

$>$ Priede IG, Merrett NR (1996) Estimation of abundance of abyssal fishes demersal fishes; a comparison of data from trawls and baited cameras. J Fish Biol 49(Supp A):207-216

Priede IG, Smith KL Jr, Armstrong JD (1990) Foraging behavior of abyssal grenadier fish: inferences from acoustic tagging and tracking in the North Pacific Ocean. Deep-Sea Res A 37:81-101

Priede IG, Bagley PM, Armstrong JD, Smith KL Jr, Merrett NR (1991) Direct measurement of active dispersal of foodfalls by deep-sea demersal fishes. Nature 351:647-649

Priede IG, Bagley PM, Smith KL Jr (1994) Seasonal change in activity of abyssal demersal scavenging grenadiers Coryphaenoides (Nematonurus) armatus in the eastern North Pacific Ocean. Limnol Oceanogr 39:279-285

Priede IG, Dreary AR, Bailey DM, Smith KL (2003) Low activity and seasonal change in population size structure of grenadiers in the oligotrophic abyssal central North Pacific Ocean. J Fish Biol 63:187-196

Priede IG, Froese R, Bailey DM, Bergstad OA, Jones EG, King $\mathrm{N}$ (2006) The absence of sharks from abyssal regions of the world's oceans. Proc Biol Sci 273:1435-1441

Priede IG, Godbold JA, King NJ, Collins MA, Bailey DM, Gordon JD (2010) Deep-sea demersal fish species richness in

Editorial responsibility: Paul Snelgrove, St. John's, Newfoundland, Canada the Porcupine Seabight, NE Atlantic Ocean: global and regional patterns. PSZN I: Mar Ecol 31: 247-260

Rowe GT, Polloni PT, Horner SG (1974) Benthic biomass estimates from the northwestern Atlantic ocean and northern Gulf of Mexico. Deep-Sea Res Oceanogr Abstr 21:641-650

Small GJ (1981) A review of the bathyal fish genus Antimora (Moridae: Gadirformes). Proc Calif Acad Sci 42:341-348

Smith CR (1985) Food for the deep sea: utilization, dispersal, and flux of nekton falls at the Santa Catalina Basin floor. Deep-Sea Res A 32:417-442

Snelgrove PVR, Haedrich RL (1985) Structure of the deep demersal fish fauna off Newfoundland. Mar Ecol Prog Ser 81:205-213

Stefanescu C, Rucabado J, Lloris D (1992) Depth-size trends in western Mediterranean demersal deep-sea fishes. Mar Ecol Prog Ser 81:205-213

Stein DL, Pearcy WG (1982) Aspects of reproduction, early life history, and biology of macrourid fishes off Oregon, USA. Deep-Sea Res A 29:1313-1329

> Stockton WL, DeLaca TE (1982) Food falls in the deep sea: occurence, quality, and significance. Deep-Sea Res A 29:157-169

Takahashi M, Iwami T (1997) The summer diet of demersal fish at the South Chetland Islands. Antarct Sci 9:407-413

$>$ Wagner HJ (2001) Brain areas in demersal fishses. Brain Behav Evol 57:301-316

Yamamura O, Inada T (2001) Importance of micronekton as food of demersal fish assemblages. Bull Mar Sci 68:13-25

> Yau C, Collins MA, Bagley PM, Everson I, Nolan CP, Priede IG (2001) Estimating the abundance of Patagonian toothfish Dissostichus eleginoides using baited cameras: a preliminary study. Fish Res 51:403-412

Yau C, Collins MA, Bagley PM, Everson I, Priede IG (2002) Scavenging by megabenthos and demersal fish on the South Georgia slope. Antarct Sci 12:16-24

> Yeh J, Drazen JD (2009) Depth-zonation of megafaunal scavengers of the Hawaiian Islands. Deep-Sea Res I 56: $251-266$

Submitted: August 19, 2010; Accepted: December 1, 2010 Proofs received from author(s): February 9, 2011 